Supplement of Earth Surf. Dynam., 8, 1-15, 2020 https://doi.org/10.5194/esurf-8-1-2020-supplement (C) Author(s) 2020. This work is distributed under the Creative Commons Attribution 4.0 License.

(c) (1)

Supplement of

\title{
Potential links between Baltic Sea submarine terraces and groundwater seeping
}

Martin Jakobsson et al.

Correspondence to: Martin Jakobsson (martin.jakobsson@geo.su.se)

The copyright of individual parts of the supplement might differ from the CC BY 4.0 License. 


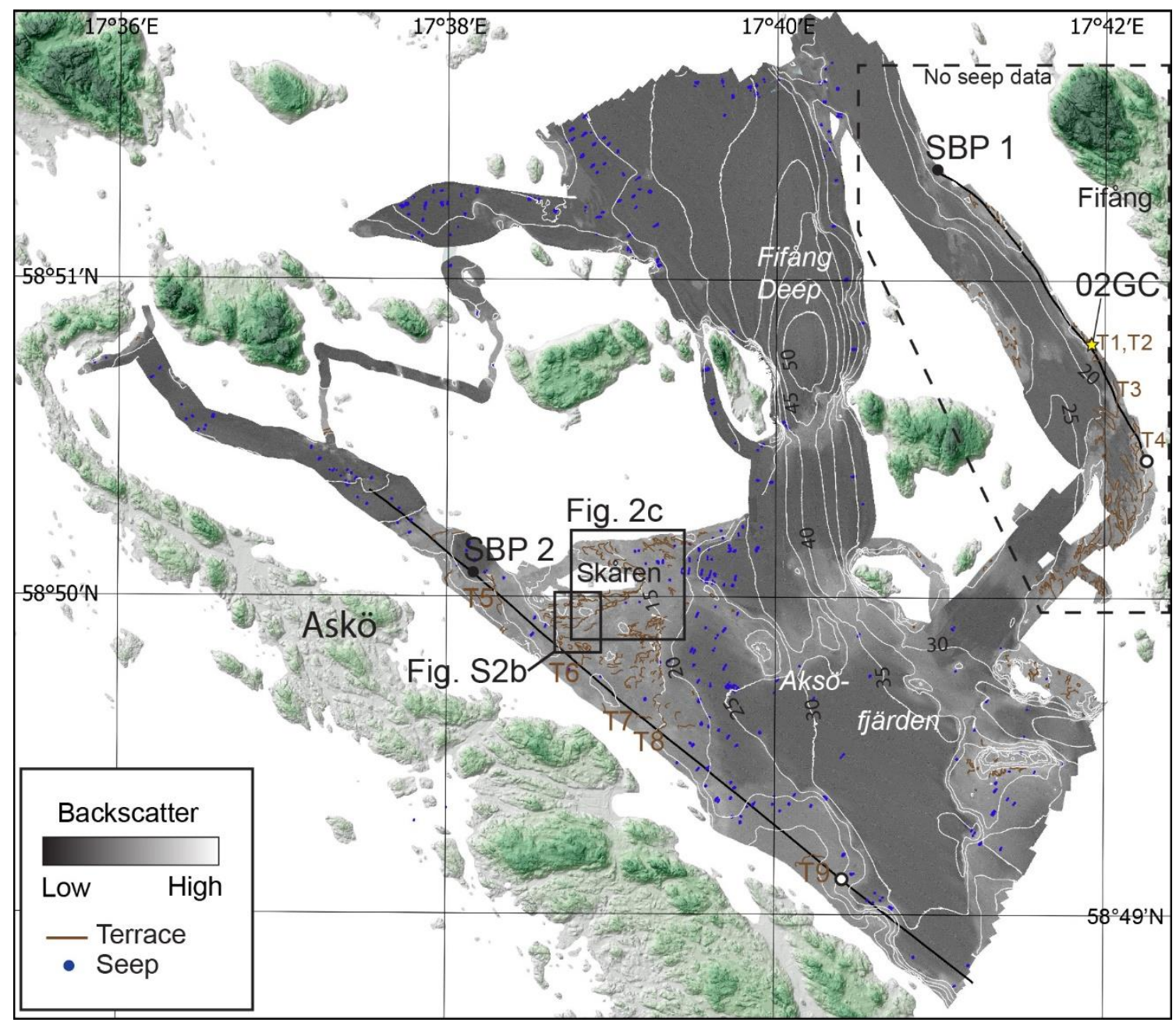

Figure S1. Multibeam backscatter map of the surveyed area east of the island Askö, Stockholm Southern Archipelago. The terraces systematically appear in a relatively harder seafloor characterized by higher backscatter values while the seeps generally occur in a softer seabed represented by lower backscatter. The location of Figure $2 \mathrm{c}$ in the main article is shown as a reference. 

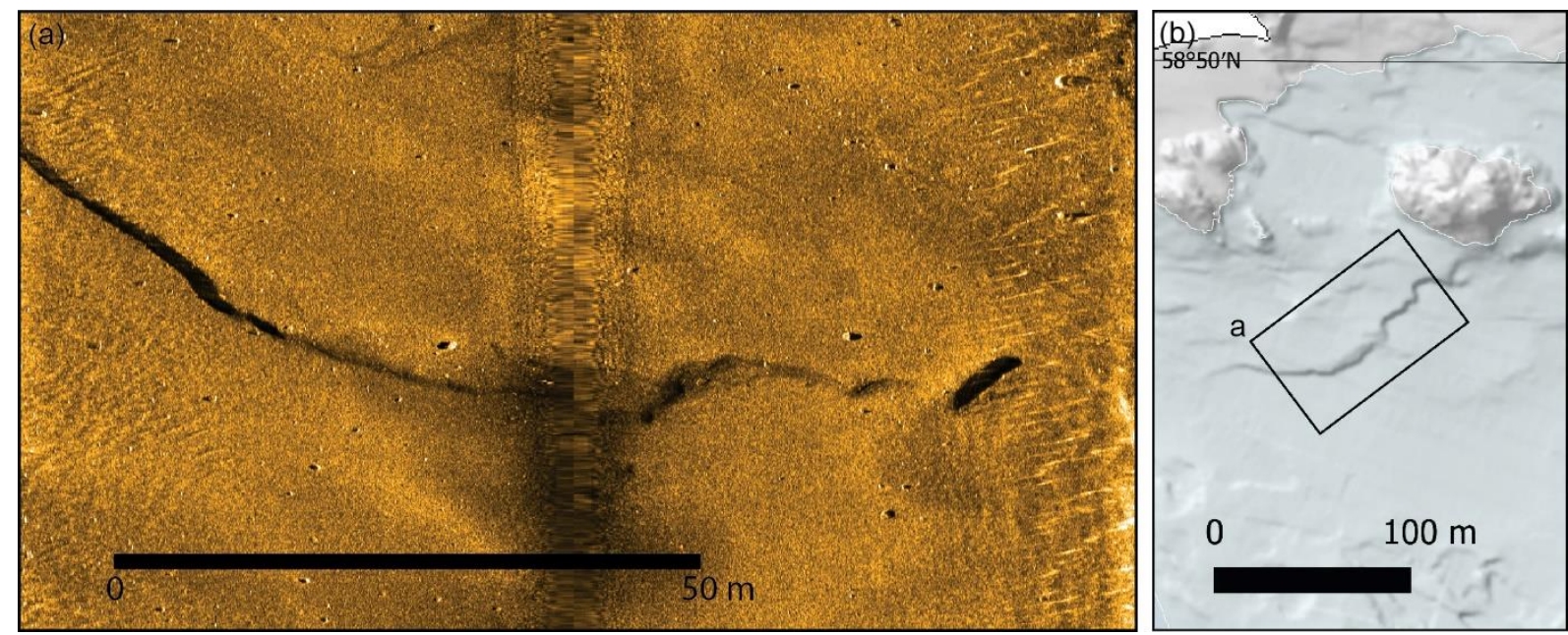

Figure S2. Side-scan imagery acquired in 2013 of a terrace also mapped with high-resolution multibeam bathymetry. The location of the slant-range corrected side-scan image (a) is marked by the black box in (b). The location of the area in (b) is shown in Figure S1. 


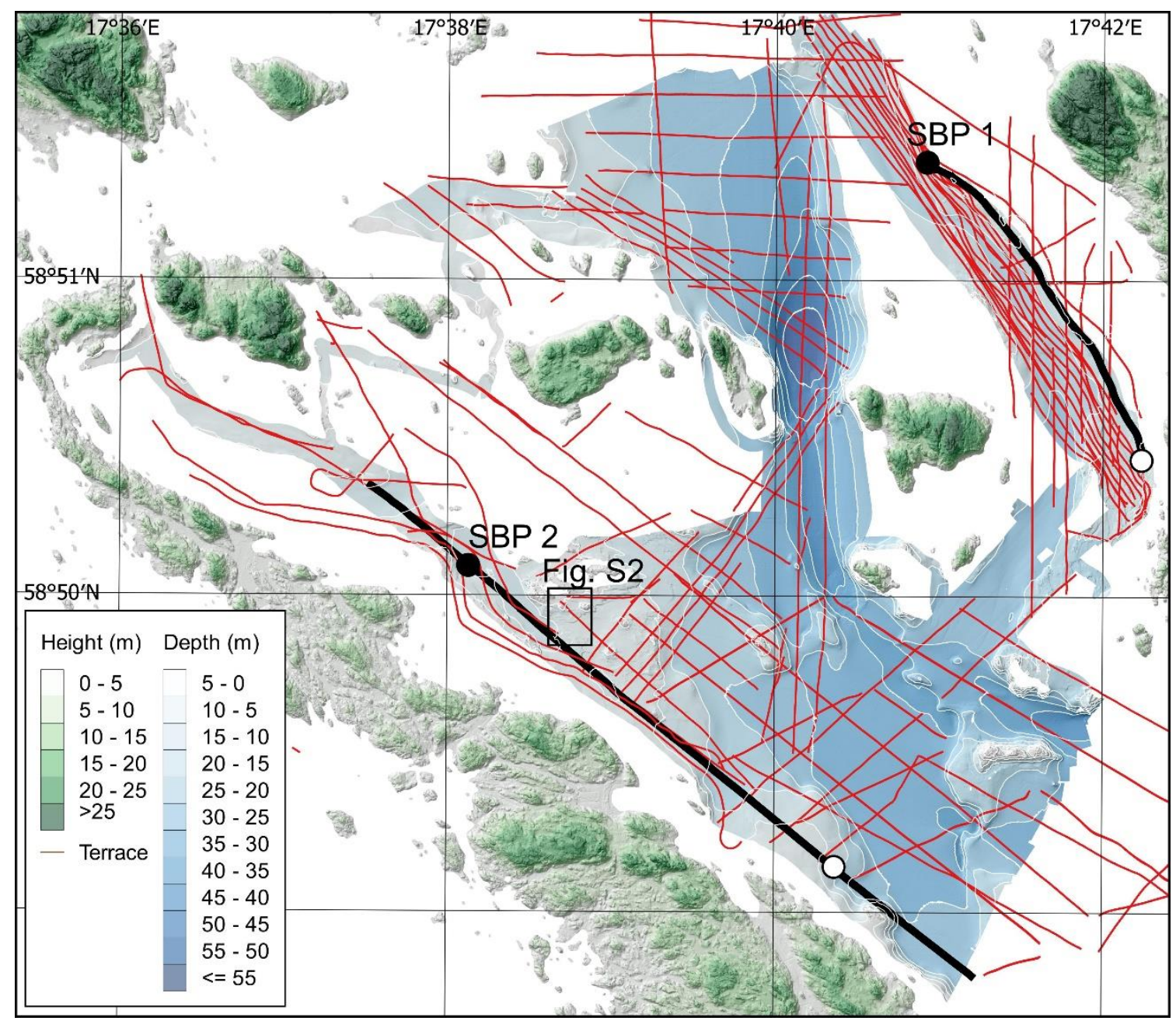

Figure S3. Map showing the semi-regular grid of sub-bottom profiles in the area east of the island Askö. 


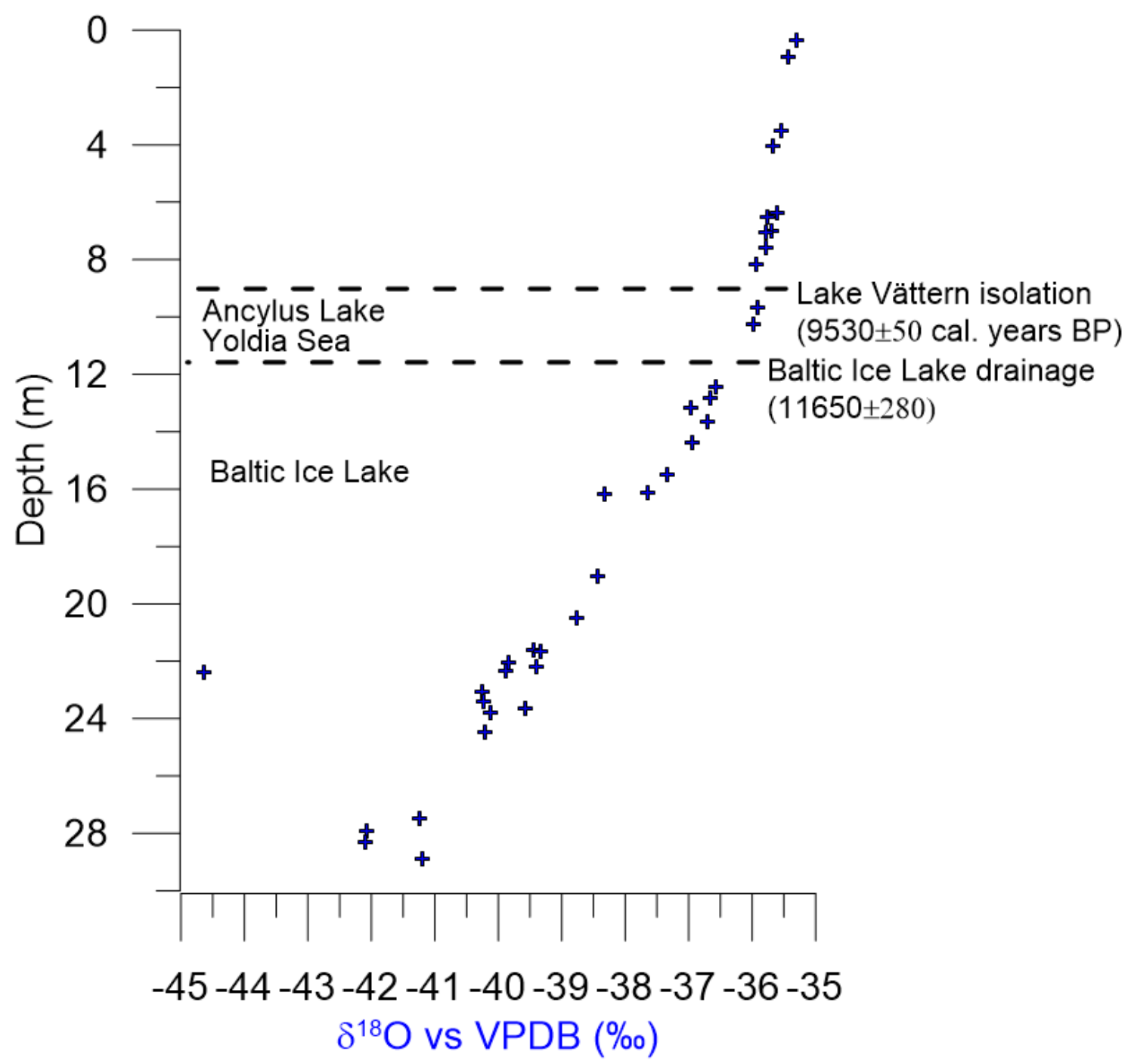

Figure S4. Measured $\delta^{18} \mathrm{O}$ in poor water retrieved from a $74 \mathrm{~m}$ long sediment drilled in Lake Vättern, Southern Sweden. Only the upper $30 \mathrm{~m}$ of the core is shown. The inferred ages of the Baltic Sea stages, the drainage of the Baltic Ice Lake and final isolation of Lake Vättern are from Swärd et al. (2018). 
(a)

Groundwater level (Haninge_3 station)

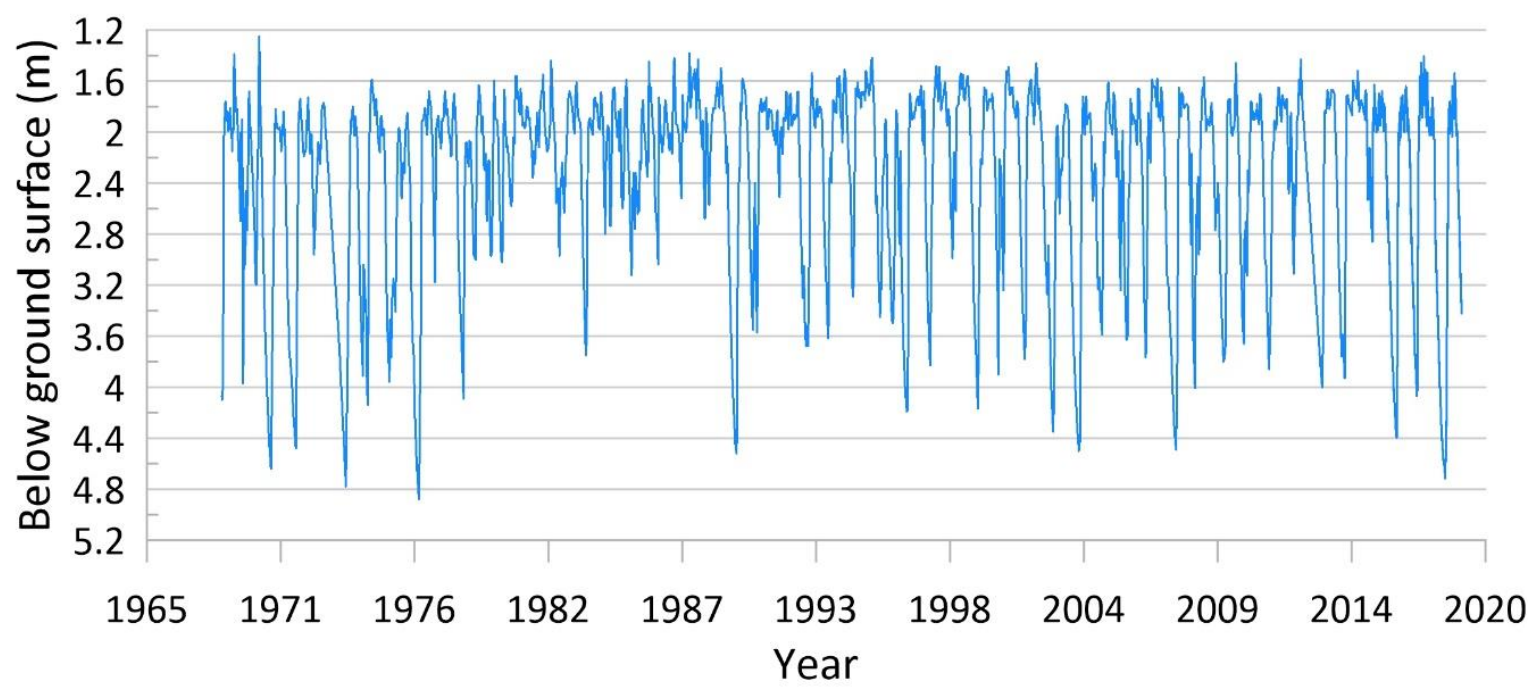

(b) Groundwater level (Haninge_3 station)

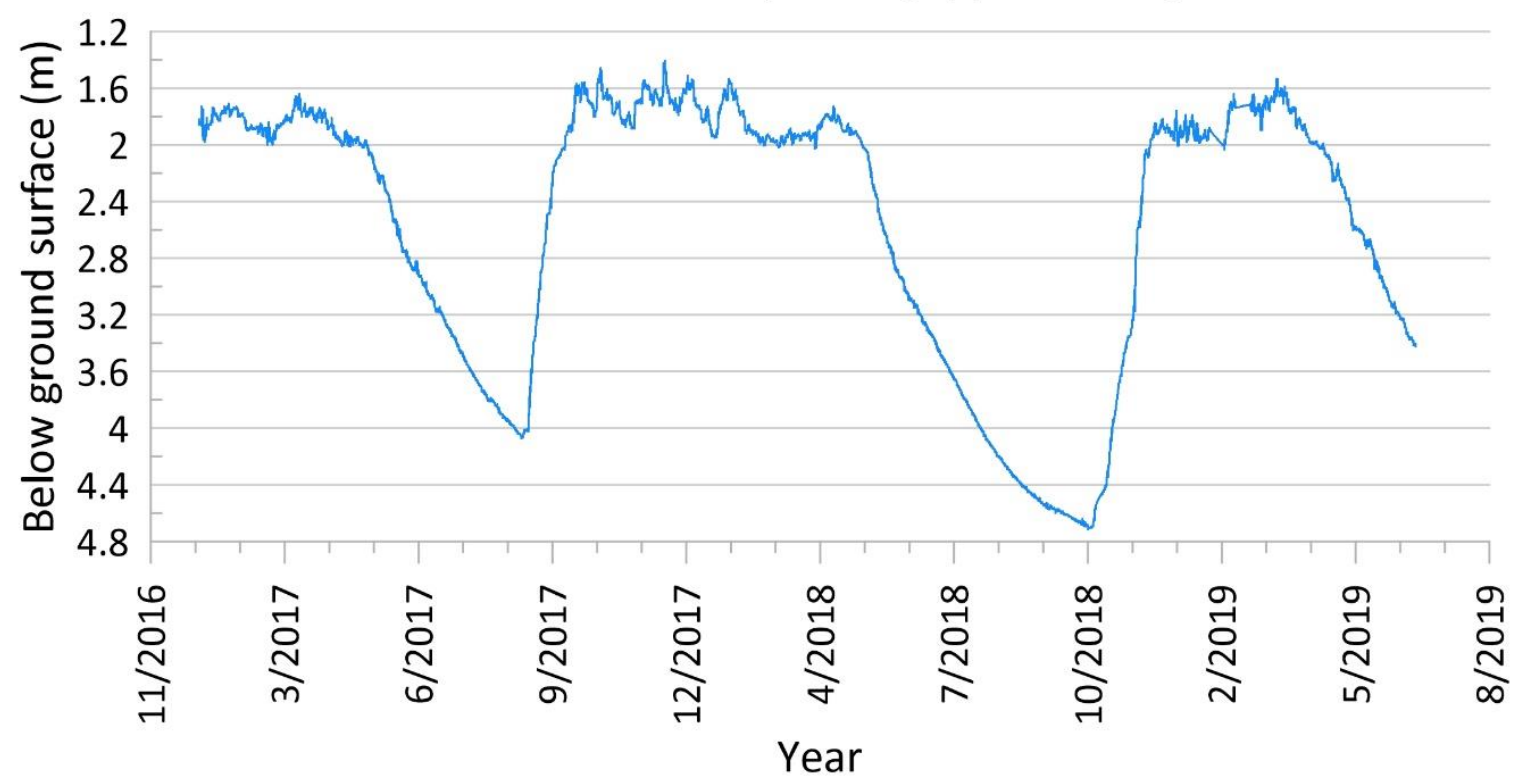

Figure S5. Fluctuations of the groundwater level in the Haninge_3 station located in Haninge, south of Stockholm. (a) Fluctuation between 1965 and 2019, with the last two years displayed in detail in (b). Data are from the Swedish Geological Survey (https://www.sgu.se/produkter/geologiskadata/oppna-data/grundvatten-oppna-data/ ).

\section{References}

Swärd, H., O'Regan, M., Björck, S., Greenwood, S. L., Kylander, M. E., Mörth, C. M., Pearce, C., and Jakobsson, M.: A chronology of environmental changes in the Lake Vättern basin from deglaciation to its final isolation, Boreas, 47, 609-624, doi:10.1111/bor.12288, 2018. 